\title{
AS NARRATIVAS DOCENTES EM DIÁRIOS ONLINE E O PARADIGMA
}

EDUCACIONAL EMERGENTE

\section{THE TEACHERS NARRATIVES IN ONLINE JOURNALS AND THE EMERGING EDUCATIONAL PARADIGM}

\author{
Simone Lucena ${ }^{1}$ \\ Socorro Aparecida Cabral Pereira ${ }^{2}$
}

\begin{abstract}
Resumo: $\mathrm{O}$ artigo discute alguns pressupostos do paradigma educacional emergente proposto por Moraes (2005) em sintonia com a utilização das tecnologias da informação e comunicação, tendo como interface de destaque o blog. A abordagem metodológica utilizada foi a pesquisaformação. Esta metodologia traz como principal característica a importância do pesquisador vivenciar reflexões sobre o processo formativo juntamente com os sujeitos da pesquisa, e assim potencializar momentos fecundos de formação sobre o que foi observado, percebido e sentido na itinerância ao longo do trabalho. O campo de reflexão teórica é a análise das narrativas dos bolsistas de iniciação à docência do Programa Institucional de Bolsa de Iniciação à Docência (Pibid) da Universidade Estadual do Sudoeste da Bahia (UESB) no curso de Pedagogia - Anos Iniciais do Ensino Fundamental. A pesquisa mostra a importância de práticas de formação inicial no contexto da cibercultura, desafiando os discentes a vivenciarem, compreenderem e experimentarem diferentes interfaces, que nascem com o movimento contemporâneo das tecnologias, aprendendo com a não-linearidade do meio digital e a abertura a múltiplas manipulações proporcionadas pela comunicação interativa e colaborativa.
\end{abstract}

Palavras-Chave: Blogosfera; formação docente; interatividade; colaboração.

Abstract: The article discusses some assumptions of the emerging educational paradigm proposed by Moraes (2005) in line with the use of information and communication technologies, with a highlight on the blog interface. The methodological approach was the research-training. This methodology has as main feature the importance of research experience reflections on the educational process with the subjects, and thus enhance fruitful moments of training on what was observed, perceived and felt in roaming throughout the work. The theoretical reflection field is the analysis of the narratives of initiation scholarship to teaching the Institutional Program Initiation Grant to Teaching of the State University of Bahia in the Faculty of Education - Years Elementary School Initials. Research shows the importance of initial training practices in the context of cyberculture, challenging students to experience it, understand and experience different interfaces, born with the contemporary movement of technologies, learning from the nonlinearity of the digital medium and openness to multiple manipulations provided by the interactive and collaborative communication.

Keywords: Blogosphere; teacher training; interactivity; collaboration.

\footnotetext{
${ }^{1}$ Doutora em Educação pela Universidade Federal da Bahia. Mestre em Educação pela Universidade Federal de Santa Catarina. Graduada em Pedagogia pela Universidade do Estado da Bahia. Professora do Departamento de Educação da Universidade Federal de Sergipe (UFS) Campus Prof. Alberto Carvalho. Professora permanente do Programa de Pós-graduação em Educação da UFS. E-mail: sissilucena@ gmail.com.

${ }^{2}$ Doutoranda em Educação no Programa de Pós-Graduação em Educação da Universidade Federal de Sergipe (UFS). Professora do Departamento de Ciências Humanas e Letras da Universidade Estadual do Sudoeste da Bahia. E-mail: socorroleti@hotmail.com.
} 


\section{Introdução}

Nas observações mais amplas sobre transformações no mundo contemporâneo, presenciamos uma série de mudanças que estão ocorrendo de forma extremamente complexa em diferentes frentes: desenvolvimento tecnológico, globalização, o desemprego, crise ambiental, a crise do conhecimento, novas formas de trabalho. A velocidade e o grande número de informações destacam-se nesse cenário. A mudança de ordem tecnológica tem sido estruturante às demais transformações, pois as tecnologias de informação e comunicação (TIC) tem possibilitado a criação de novas redes que interligam pessoas, objetos, lugares e máquinas em espaços outros onde novos conhecimentos são construídos e/ou compartilhados, desafiando as instituições a repensarem o seu papel frente às transformações econômicas, sociais, políticas e culturais.

Nesse contexto, faz-se necessário pensar a formação inicial de professores no sentido de romper com propostas de formação pautada na racionalidade técnica, que abordam os currículos de forma dicotômica em teoria e prática separando-as em espaços e tempos que não se inter-relacionam. Esta concepção de formação não dá mais conta das demandas colocadas para a profisssão docente que necessita de um professor capaz de ser um "agente dinâmico cultural, social e curricular" (IMBERNÓN, 2011, p. 22).

Em sintonia com essas demandas o Ministério da Educação (MEC) criou o Programa Institucional de Bolsa de Iniciação à Docência (Pibid), um programa executado pela Coordenação de Aperfeiçoamento de Pessoal de Nível Superior (Capes). Este programa foi criado por meio do Decreto № 7.219, de 24 de junho de 2010, que no Art. $1^{\text {o }}$ estabelece como finalidade do Pibid "fomentar a iniciação à docência, contribuindo para o aperfeiçoamento da formação de docentes em nível superior e para a melhoria de qualidade da educação básica pública brasileira". As bases legais do Pibid, além do citado Decreto, são as leis nº 9.394/1996 e a ${ }^{\circ} 12.796 / 2013$.

Trata-se de um programa inicial de formação de professores que visa entre outros objetivos inserir os licenciandos no cotidiano de escolas da rede pública de educação, proporcionando-lhes oportunidades de criação e participação em experiências metodológicas, tecnológicas e práticas docentes de caráter inovador e interdisciplinar que busquem a superação de problemas identificados no processo de ensino-aprendizagem. Como programa de formação, tem ainda como objetivo produzir inovações na articulação entre escolas e universidade.

O Pibid - Anos Iniciais do Ensino Fundamental da Universidade Estadual do Sudoeste da Bahia (UESB), tem investido em uma proposta metodológica que contemple as pautas contemporâneas, especialmente no diz respeito a reflexão, a pesquisa e à inserção da cultura 
digital na formação dos professores, através de diferentes ambientes de aprendizagem, que vem estruturando toda a proposta do programa, avançando no sentido do rompimento de uma comunicação de massa, para uma dinâmica mais interativa e colaborativa.

Para a realização das narrativas da formação no programa, os discentes foram desafiados a registrarem seu processo formativo, buscando descrever, analisar, refletir sobre os acontecimentos e situações cotidianas da sua formação. Para a escrita desses registros, os alunos mobilizam saberes de suas fontes pré-profissionais, saberem científicos e principalmente saberes construídos na experiência da sala de aula e da escola.

Desta forma, entendemos que as TIC são elementos estruturantes na formação de professores e não um mero recurso tecnológico. Em geral, no cenário de formação e da emergência da internet, muitas propostas tem subutilizado os ambientes e interfaces online de aprendizagem para reproduzem uma pedagogia pautada numa visão instrucionista, que esvazia os sentidos e significados de uso dessas tecnologias na educação.

Nessa perspectiva, Demo (2003, p. 78) critica essa concepção da educação ao afirmar:

Num primeiro momento, instrucionismo é "linearizar" a aprendizagem no plano da mera lógica sequencial, tornando-a reprodutiva e mantendo o aprendiz na condição de objeto. Num segundo momento, o instrucionismo evita o saber pensar, ou seja, uma das bases mais flagrantes da autonomia, induzindo à subalternidade.

O autor continua a análise, retratando que na nova mídia encontramos essa abordagem, a exemplo da proposta da teleconferência, utilizada muitas vezes como panacéia de alguns cursos a distância. Assim, a centralização e a exposição unilateral não desafiam o sujeito na construção de seu processo de aprendizagem, já que "esta aparece em outro ambiente, tipicamente reconstrutivo-político, no qual o aluno é convidado a pesquisar e elaborar com mão própria para poder manejar conhecimento com autonomia" (DEMO, 2003, p. 79). Contudo, sua utilização exclusiva não dá conta das demandas dos sujeitos envolvidos no processo. Na visão de Pretto (1996, p. 114), “[...] o uso como instrumentalidade esvazia esses recursos de suas características fundamentais, transformando-os apenas num animador da velha educação, que se desfaz velozmente, uma vez que o encanto da novidade também deixa de existir".

Moraes (2005) em sintonia com essas questões, nos alerta para a necessidade de superação desse paradigma, baseado em propostas de trabalho que agregam som, imagem, animação, mais que não garantem uma boa qualidade pedagógica, destacando que esses recursos tecnológicos apenas representam uma série de informações a serem repassadas aos alunos não contribuindo com a emancipação dos educandos. 
É nessa perspectiva que estaremos preparando os futuros professores para o acesso as redes de comunicação e de informação? De que forma estamos desenvolvendo atividades formativas que tenham como pressuposto a interatividade e a colaboração a parir desses recursos tecnológicos? Diante deste questionamento precisamos repensarmos a concepção de ciência e de educação que permeia esse cenário.

Nessa perspectiva, desenvolvemos uma proposta metodológica de formação, que tem como foco as narrativas em rede, a reflexão, a interatividade e a colaboração, ou seja, a imersão plena no contexto digital e no trabalho conjunto entre professores supervisores e bolsistas de iniciação a docência conforme nos sugere Moraes (2005) no paradigma emergente. Este paradigma nos impulsionou na criação dos diários online, desencadeando de forma mais efetiva essas experiências formativas. Os diários online são blogs construídos colaborativamente pelos bolsistas do Pibid que ao utilizarem esta interface tornam-se autores e atores da sua formação, pois

[...] a forma como os sujeitos, praticantes culturais, apropriam-se destes meios, passando, a partir deles, a produzir linguagens que fazem a diferença. Por estes meios ou mídias, circulam signos, informações e comunicação que possibilitam a construção de novas formas de pensar, de conceber o mundo, a política, a sociedade, a economia, a cultura e a educação. (LUCENA, 2016, p. 280).

Nesse contexto, apresentaremos aqui os pressupostos metodológicos que embasam nossa pesquisa, baseada na comunicação interativa presente nos diários online, buscando vivenciar outras formas de construção de aprendizagens a partir da inserção das TIC na educação.

\section{Pressupostos epistemológicos e metodológicos}

Segundo Moraes (2005), o grande problema da educação está no modelo de ciência, que perpetuou-se em determinado contexto histórico, e nas teorias da aprendizagem que influenciaram e fundamentaram a prática pedagógica. Nessa perspectiva, segundo a autora,

Acreditamos na existência de um diálogo interativo entre o modelo de ciência, as teorias da aprendizagem utilizadas $\mathrm{e}$ as atividades pedagógicas desenvolvidas. Na prática do professor, encontram-se subjacentes modelos de educação e de escola fundamentadas em determinadas teorias do conhecimento. Ao mesmo tempo que a educação é influenciada pelo modelo de ciência, aquela também o determina. $\mathrm{O}$ modelo de ciência que explica a nossa relação com a natureza, com a própria vida, esclarece também, a maneira como aprendemos e compreendemos o mundo, mostrando que o 


\section{Notandum 43 jan-abr 2017 - CEMOrOC - Feusp / IJI-Univ. do Porto \\ DOI: http://dx.doi.org/10.4025/notandum.43.5}

indivíduo ensina e constrói o conhecimento, a partir de como compreende a realização desses processos. (MORAES, 2005, p. 18).

Colocar em reflexão essas questões, nos faz compreender que nas práticas educacionais estão presentes modelos de educação e de escolarização que utilizam fundamentos de determinadas teorias do conhecimento. O estudo apresentado por Moraes (2005), retrata de forma clara uma visão de ciência com duas distinções fundamentais: a primeira refere-se a separação entre conhecimento científico e conhecimento proveniente do senso comum, e a segunda refere-se à separação existente entre a natureza e a pessoa humana.

Segundo a autora, com o advento da Idade Moderna tivemos a reposição do homem como senhor do mundo, onde o mesmo podia transformar a natureza e explorá-la. Observamos assim um novo método de investigação científica pautado na descrição matemática da natureza. A autora cita Descartes, ressaltando que o mesmo deduziu que a essência do pensamento humano está totalmente separada do corpo, visto como coisa externa e constituída de partes mecânicas. Temos aí a dicotomia entre o mundo dos objetos importante para o conhecimento objetivo e o mundo do sujeito, um mundo intuitivo e reflexivo, que busca conhecer em uma outra lógica.

Moraes (2005) cita também Isaac Newton e destaca que o mesmo via o mundo como uma máquina perfeita. Para Newton, Deus criou partículas materiais, a força entre elas e as leis do movimento. Tudo isso funciona como uma máquina governada por leis imutáveis, que controla a natureza e leva a ciência a pressupor a existência do determinismo universal.

Neste enfoque, temos a visão de um mundo máquina onde para conhecer era preciso quantificar, o rigor científico é pautado pelo rigor das mediações. As qualidades inerentes aos objetos não tem valor científico, para conhecer nessa lógica, é preciso dividir, classificar, para somente depois tentar compreender as coisas em separado.

Com base nesses pressupostos e seus desdobramentos na sociedade, a maioria das perspectivas educacionais estiveram pautadas em padrões de comportamento preestabelecidos, que não nos desafia a questionar, a não pensar de forma diferente, a se acomodar diante de práticas autoritárias e a ter certeza das coisas. Assim, na maioria das vezes a educação é compreendida como instrução, com destaque nas situações de sala de aula nas quais os alunos são instruídos pelo professor.

A partir de Condorcet (2008), por exemplo, compreendemos que somente uma instrução, baseada na razão e em conhecimentos rigorosos, teria a possibilidade de formar indivíduos autônomos. Para o autor, os graus de instrução deveriam ter como metas: os 
objetivos da instrução; quais os livros que devem servir para cada ensino e que outros meios é preciso acrescentar a eles; quais devem ser os métodos de ensino; que mestres devem ser escolhidos, por quem devem ser escolhidos e como se deve escolhê-los. Na visão do autor, o enfoque é dado somente a questões relativas a razão, transmissão de conteúdos, nos meios e matérias de ensino, deixando de lado questões características do ser humano como a emoção e a subjetividade.

Locke (1983) argumenta que a experiência é responsável pelas ideias que habitam a nossa mente. Assim, o conhecimento está fora do homem. Nessa perspectiva, para o autor, a experiência é que dá sustentação ao conhecimento, que nos abastece de ideias que nos possibilitam compreender melhor o mundo. Segundo Locke teríamos duas fontes de ideias: a sensação, que diz respeito a percepção de objetos sensíveis e particulares e a reflexão ou sentido externo potencializado pelas nossas operações mentais com as ideias que aprendemos pela sensação.

Percebemos nesses fundamentos uma concepção de educação que traduzem uma visão empirista em que o conhecimento ocorre somente através dos sentidos. É algo que vem do mundo do objeto (meio físico e social) e este é determinante do sujeito e não o contrário. Assim, a visão empirista caracteriza-se pela unidirecionalidade nas relações sujeito-objeto: é admitida como determinante a interferência do objeto sobre o sujeito e não o contrário.

As implicações dessas perspectivas para educação estão pautadas no professor como transmissor de conteúdos e os alunos como "tábula rasa", produzindo seres subservientes, obedientes, castrados em sua capacidade criativa, destituídos de outras formas de expressão e solidariedade. Além disso, teríamos um conteúdo voltado à aquisição de noções com ênfase na assimilação e conhecimento acumulado, com metodologias pautadas em aulas expositivas e a reprodução de exercícios de fixação em leituras e cópias.

Para Moraes (2005), o indivíduo aprende não apenas usando a razão, o intelecto, mais também a intuição, as sensações, as emoções, os sentimentos. Nesse sentido, as propostas de formação de professores que utilizam atividades online na internet, podem reproduzir o mesmo modelo de educação que vem sendo duramente muito tempo criticados por diferentes concepções pedagógicas, apenas camuflando-se de inovadores. Algumas propostas de ambientes de aprendizagem vem sendo construídas tendo como base o instrucionismo e a disponibilização de informações, sem levar em conta aspectos voltados para a subjetividade, interação, colaboração e autoria dos alunos.

Nessa lógica, muitas atividades vivenciadas nestes ambientes continuam pautadas na lógica da distribuição da informação, na cópia na reprodução, e na linearidade desconsiderando 
projetos educativos que favoreçam o trabalho cooperativo potencializado pelo meio digital. Dessa forma, propostas fechadas, tendo como base a linearidade e transmissão dos conteúdos e que não dialogam com o contexto se tornam sem relevância para o educando, transformandoos em meros repetidores de um currículo sem significado. Essa mesma noção de ordem, tão vivenciada na escola, traz no seu bojo a ideia de professor "dono da verdade" e "detentor de todo o saber".

Ao utilizar as TIC na educação, algumas práticas, acabam reforçando a perspectiva intuicionista, na medida em que estas tecnologias só são utilizadas como recurso didático para endossar a lógica linear da aula expositiva. Vale destacar, que não estamos descartando a aula expositiva, pois acreditamos que a mesma é importante para contribuir com síntese de estudos, abertura de um tema, ou na perspectiva de se abrir um diálogo com os alunos, contribuindo com novas reflexões. Entretanto, ela sozinha não dá conta das diferentes necessidades dos educandos (PEREIRA, 2008).

Os fundamentos vigentes em educação, pautados numa visão linear e mecanicista, sinalizam a necessidade de buscarmos o rompimento com os pressupostos da ciência clássica e a edificação de um pensamento pedagógico capaz sintonizar com as exigências atuais da sociedade. Em especial as propostas de formação de professores que trabalham com as tecnologias da informação e comunicação, precisam repensar suas formas de ensinar e de aprender. É nessa perspectiva que comungamos com Moraes (2005), no sentido de pensarmos um outro paradigma que possibilite pensar em novas perspectivas de educação, onde destaquese o pensamento divergente, a criatividade, a colaboração a interação e as relações.

Moraes (2005) assinala que a teoria da relatividade e da física quântica constituem as tentativas mais completas de desenvolvimento de uma abordagem global do funcionamento das leis do universo relacionadas à matéria e ao movimento. A autora esclarece que na perspectiva dessa teoria tudo que está no ambiente flui de dentro do sujeito por meio da percepção humana captada pelos órgãos do sentido, contribuindo dessa forma para a formação do pensamento, mostrando a interação entre ambos, ajudando assim a resgatar a visão de contexto como condição fundamental para a sobrevivência da humanidade.

Além disso, para esta autora,

A física quântica oferece a visão de totalidade, esclarece a multidimensionalidade do processo educativo, mostrando que o conhecimento decorre dos aspectos inseparáveis e simultâneos que envolvem os aspectos físico, biológico, mental, psicológico, cultural e social. (MORAES, 2005, p. 23). 
Observamos na concepção da autora uma visão de totalidade e interdependência entre o ambiente e o pensamento, onde conceitos e teorias estão conectados entre si. Nessa lógica, o indivíduo aprende não apenas por meio de instrução e sim usando todo o seu potencial intuitivo, suas sensações, emoções e sentimentos, formando assim uma unidade cérebro e espírito.

A partir dessas considerações, Moraes (2005) afirma que saímos de uma era material para uma era das relações tendo como base a teoria da relatividade e na descrição unificada dos fenômenos atômicos trazidos pela teoria quântica. A autora enfatiza que a era das relações requer a criação de novos ambientes de aprendizagem que destaquem a circulação de informações, a construção do conhecimento pelo aprendiz, o desenvolvimento da compreensão e, se possível o alcance da sabedoria objetivada pela evolução da consciência individual e coletiva.

\section{$O$ desafio da interatividade e o paradigma emergente}

A criação de novos ambientes de aprendizagem na internet e o desenvolvimento do paradigma emergente, requer repensarmos a abordagem pedagógica e comunicacional nas propostas metodológicas de cursos voltados para a formação de professores. A simples disponibilização de programas visivelmente agradáveis, coloridos, bonitos com muita animação e imagem, não garantem a participação ativa do aluno, sua interação com os demais colegas e a construção de uma perspectiva pautada na construção do conhecimento e na interatividade.

Nessa lógica, precisamos avançar para processos comunicacionais que garantam uma maior interatividade na rede. Assim, a linguagem digital potencializada pelas TIC, tendo como principais características a plasticidade, flexibilidade e rapidez nos bits, possibilitam uma maior interatividade nos espaços online, mudando consideravelmente a ação de docentes e discentes. A interatividade se constitui num dos fundamentos da cibercultura, pois possibilidade de intervenção e participação na mensagem.

Entretanto, existem várias concepções do termo interatividade, desde abordagens centradas nos fluxos de emissão e recebimento, passando pela ação dialógica homem-máquina, relação mensagem-meio, até uma visão mais ampliada que remete à fusão emissão-recepção que extrapola o meio digital. Discutiremos aqui os fundamentos da interatividade baseados em Alex Primo (2007) e Marco Silva (2003), por compreendermos que os dois autores avançam na discussão dessa temática.

Primo (2007), faz uma crítica a visão de interação baseada apenas em questões de infraestrutura informática, que reduzem as questões a uma abordagem tecnicista. Exemplo disso são as discussões fundamentadas apenas na questão da programação e autonomização de 
processos, velocidade de respostas dos usuários etc. $\mathrm{O}$ autor segue argumentando que a redução do tema interação a meros aspectos tecnológicos, é desprezar toda uma rede de complexidade nesse contexto.

Na visão de Primo (2007, p. 100),

O estudo das interações mediadas por computador deve partir de uma investigação das relações mantidas, e não dos participantes em separado, ou seja, é preciso observar o que se passa entre os integrantes. A partir disso, se poderá compreender as diferenças qualitativas dos processos qualitativos das interações mediadas por computador.

Nessa lógica, o autor distingue a interação mútua da interação reativa. Na interação mútua, o relacionamento é definido e redefinido ao longo da própria interação. Esse tipo de interação opõe-se a causalidade linear - pois uma ação não conduz necessariamente a outra -, é apenas no contexto do relacionamento que a relação vai se transformando e evoluindo. Além disso, para esse autor, a interação mútua traz como características principais a sua construção dinâmica, contínua e contextualizada. Nessa perspectiva, a interação mútua é uma ação conjunta do emissor e do receptor, muito mais que um simples movimento ou reação determinada. Logo, jamais teríamos um relacionamento igual ao outro.

Contrapondo-se a interação mútua, Primo (2007) traz a concepção da interação reativa, baseada na previsibilidade e na automatização das trocas. Assim, para o autor, se um ato fugir do que foi programado, o mesmo pode ser ignorado e até mesmo recusado ao longo do processo e até mesmo acabar com a situação interativa.

Primo (2007, p. 154) enfatiza que,

Diferentemente da interação mútua que promove a invenção conjunta de soluções temporárias aos problemas, durante a própria interação e em virtude dos fatores contextuais envolvidos, o desenvolvimento da interação reativa depende das fórmulas previstas (que viabilizam a própria interação). Em vez de ser negociada a relação insiste em perseguir os trilhos de marcados.

Sendo assim, a discussão sobre a interação mediada por computador não pode ser reduzida simplesmente ao potencial técnico das máquinas, esquecendo-se das complexas relações entre os sujeitos envolvidos no processo. Na educação online, por exemplo, essa visão é reducionista, por desconsiderar as trocas interativas entre os participantes e reduzir a relação a um processo mecânico de envio e recebimento de mensagens.

Sob outra perspectiva Silva (2002), apresenta-nos a emergência histórica da interatividade a partir de três esferas que estão imbricadas: a esfera tecnológica, a esfera 
mercadológica e a esfera social. No aspecto tecnológico, teríamos como destaque o computador e a sua infinita possibilidade do indivíduo modificar o conteúdo. Entretanto, o autor argumenta que apenas essa esfera é responsável pela evolução da infotecnologia. É preciso, além disso, observar a importante disposição por parte do usuário e também a disposição social em termos de conteúdo. Já em relação a esfera mercadológica, o autor enfatiza a importância de uma maior interação entre empresário e consumidor. É relevante observar que não basta ao empresário uma simples exposição dos seus produtos na rede. É necessário que as imagens disponibilizadas estejam abertas a experiência de adentramento, participação e intervenção ativa no conteúdo da mensagem. A esfera social traz como principal características a emergência do controle remoto, como contribuição inicial nesse contexto. Teríamos também o surgimento do controle remoto e do videogame, que possibilitaram ao sujeito a emissão separada da recepção.

Colocar em reflexão essas questões requer a superação da lógica da comunicação pautada na unidirecionalidade, onde a figura do emissor e do receptor supostamente passivo é criticada por Silva (2002). Este autor propõe uma configuração comunicacional, onde a participação ativa do sujeito é apresentada através da tríade comunicacional emissão-recepçãomensagem, demonstrada no Quadro 1 que traz a comparação entre as modalidades de comunicação unidirecional e interativa:

Quadro 1 - COMPARAÇÃO ENTRE AS MODALIDADES DE COMUNICAÇÃO ENTRE
AROFESSOR-ALUNO
\begin{tabular}{|l|l|}
\hline \multicolumn{2}{|c|}{ A COMUNICAÇÃO } \\
\hline MODALIDADE UNIDIRECIONAL & MODALIDADE INTERATIVA \\
\hline $\begin{array}{l}\text { MENSAGEM: fechada, imutável, linear, } \\
\text { seqüencial. }\end{array}$ & $\begin{array}{l}\text { MENSAGEM: modificável, em mutação, na } \\
\text { medida em que responde às solicitações daqueles } \\
\text { que a manipulam. }\end{array}$ \\
$\begin{array}{l}\text { EMISSOR: "contador de histórias", narrador, que } \\
\text { atrai o receptor (de maneira mais ou menos sedutora } \\
\text { e/ou por imposição) para o seu universo mental, seu } \\
\text { imaginário, sua récita. }\end{array}$ & $\begin{array}{l}\text { EMISSOR: “designer de software”, constrói uma } \\
\text { rede (não uma rota) e define um conjunto de } \\
\text { territórios a explorar; ele não oferece uma história a } \\
\text { ouvir, mas um conjunto intrincado (labirinto) de } \\
\text { territórios abertos a navegações e dispostos a } \\
\text { interferências, a modificações. }\end{array}$ \\
RECEPTOR: assimilador passivo. & $\begin{array}{l}\text { RECEPTOR: "usuário", manipula a mensagem } \\
\text { como co-autor, co-criador, verdadeiro conceptor. }\end{array}$ \\
\hline
\end{tabular}

Fonte: Silva (2002, p. 73)

Como forma de experienciar a modalidade de comunicação interativa na formação inicial de professores propomos aos bolsistas de iniciação à docência do Pibid a criação de blogs como espaço de comunicação, interação, produção e reflexão. Vale ressaltar, que para que a modalidade interativa aconteça o professo precisará ser o responsável pela mediação e 
disponibilização de uma estrutura hipertextual que busque transformar imagem, som e texto em algo essencialmente navegável e manipulável. É preciso também desafiar os alunos a serem gestores dos meios de comunicação, abrindo um leque de possibilidades para que os mesmos possam intervir na mensagem.

\section{O potencial interativo dos blogs}

Nesse processo de reflexão, trabalhando com a proposta de Pesquisa Formação no Pibid, utilizamos o potencial formativo dos diários online, na interface blog, pois o mesmo abre a possibilidade dos alunos exercerem sua autoria, produzindo conhecimento, agregando vídeos, imagens, sons, criando links, além de vivenciar processos colaborativos e interativos num ambiente aberto à visitação de seus colegas e internautas da rede. Esse aspecto foi de suma importância no desenvolvimento das ações do programa, abrindo espaço para uma melhor comunicação entre os alunos, no sentido de contribuir com uma dinâmica mais interativa, reflexiva e colaborativa de trabalho, pois alguns bolsistas residiam em cidades diferentes.

Sendo assim, essa perspectiva de trabalhar os diários no blog, permitem, aos alunos do programa a discussão sobre as problemáticas vivenciadas nas aulas, bem como a busca de soluções coletivas sobre a ação. Como forma de garantir o cumprimento dessas finalidades, os bolsistas do Pibid além de sistematizarem suas reflexões sobre a prática docente nos blogs, são desafiados a comentar no blog dos colegas, identificando assim que muitos dos desafios vivenciados pelos parceiros são também vivenciados no âmbito da sua docência.

Destacamos o blog da aluna A5 um processo interativo com os colegas, supervisores e coordenadores do Pibid.

\footnotetext{
Aluna A1: Gostei do seu relato A5! E é como você disse: esse segundo diagnóstico vai servir para planejarmos novas ações, nas quais vamos adquirir mais experiência.
}

Professor Supervisor 2: A5, Querida concordo com você em continuarmos com o mesmo método para que eles possam avançar na leitura e na escrita, espero de coração chegarmos no final desse ano essas crianças possa estar no nível alfabético, todas sem exceção; vai ser uma festa.

PP: Suas reflexões demonstram conhecimento da turma e implicação com sua formação. Gostaria que você trouxesse reflexões sobre a importância da pesquisa na sua formação.

Aluno A5: A pesquisa tem sido fundamental na minha formação, pois nos dá uma dimensão da realidade da escola a qual estamos em contato. As reflexões que realizamos são fundamentais, pois é uma momento que nos possibilita a ter novos olhares.

Aluno A6: A5, percebi que em sua reflexão você descreve bastante o desenvolvimento dos alunos e como eles estão avançando, e isso é muito bom, 


\section{Notandum 43 jan-abr 2017 - CEMOrOC - Feusp / IJI-Univ. do Porto \\ DOI: http://dx.doi.org/10.4025/notandum.43.5}

pois você está vendo resultado no seu trabalho. Como se deu esse processo de planejamento, quais as fontes que você utilizou para pesquisar na construção do diagnóstico, e como esse processo contribuiu na sua formação docente e como pesquisadora.

Aluno A 5: Utilizamos os autores que estudamos (Mendonça e Mendonça) principalmente, estes falam do Método Sociolinguístico de Paulo Freire e também a matriz de referencia do MEC que também nos deu suporte para a construção do diagnóstico. Planejamos as atividades em grupo, ouvimos as opiniões dos colegas, esclarecemos algumas dúvidas e aprendemos muito através das socializações dos nossos trabalhos.

Aluno A 7: A5 realmente essa sala já tive o prazer e sei como os alunos são muito interessados e muito esforçados, porém já era nítido que alguns precisavam avançar tanto na escrita como na leitura, entretanto o trabalho que desenvolvemos com eles é de suma importância, quero saber se pra você que participou do diagnóstico se sentiu desafiada como profissional de educação em algum aspecto que precisa que eles avancem? Ou melhor o que mais te desafia como professora diante dos problemas deles apresentados? Eu particularmente acho a sala muito boa nos diversos aspectos mais claro que em todas a classe em que fomos apresentados os problemas estão para nós resolvermos sei que é preciso muita dedicação e muito amor a carreira para poder ajudar esses alunos a avançar e estabelecer sua autonomia.

Aluno A5: A7: Acredito que a arte de ensinar é sempre um desafio, pois nem sempre as coisas saem como planejamos, o que não foi o caso nesta atividade, ao ensinar sempre queremos que o aluno avance, mas nem sempre todos aprendem da mesma forma. Acredito que o maior desafio no memento é não perder as esperanças na educação e de um futuro melhor para nossas crianças. Aluno A 8: Ei A5! Com esse diagnóstico e como você mesmo fala que ensinar é sempre um desafio, como você se senti ao perceber o avanço das crianças? Teve alguma coisa no diagnóstico que vocês realizaram que você caminhando para a docência não realizaria novamente?

Observamos na dinâmica de comentários que foram emergindo a partir da narrativa de A5, aonde tanto os colegas como o professor supervisor desencadeiam um processo de interação dialógica sobre as reflexões relatadas pela discente. Concordamos então com Primo (2005, p.116), que a "interação mútua é ação conjunta, muito mais que mero movimento ou reação determinada".

Destacamos aqui o binômio bidrecionalidade-hibridização destacado por Silva (2002), nas discussões sobre interatividade, onde o autor faz uma crítica severa a uma comunicação unidirecional e aponta para uma concepção de comunicação onde não existe mais emissor separado de receptor, pois todo emissor é um receptor em potencial. Esses fundamentos são coerentes com a perspectiva de formação que acreditamos, pois abre a possibilidade de pensarmos a formação num permanente processo de troca com os colegas refletindo e interpretando os modelos apresentados pelo outro, a partir de sua imersão nas práticas 
pedagógicas no ciberespaço. Esse aspecto é fundamental na itinerância formativa, para que possamos promover novos espaços de troca de saberes entre os docentes. Outra característica que estamos percebendo em relação ao potencial dos diários em blogs, é a emergência de um trabalho colaborativo em rede, a partir dos comentários dos alunos nos blogs dos seus colegas.

A autora Kenski (2003), destaca que trabalhar de forma colaborativa abre possibilidades para que os sujeitos aprendam juntos, conviva com a diferença e, também busquem conjuntamente soluções que vão contribuir com todo o coletivo. Observamos no Pibid, que essa dinâmica é vivenciada em todas as etapas do trabalho, tanto presencial quanto online, permitindo que todos os sujeitos envolvidos aprendam com a colaboração dos outros, desde o planejamento das ações, aplicação de propostas didáticas, análise de diagnósticos e também nos desafios e reflexões explicitados pelos colegas nos comentários dos blogs dos demais. Vejamos a contribuição dos colegas no blog da bolsista A6:

\footnotetext{
Aluno 9: Maria, muito boa sua reflexão, o fazer-se professor é uma tarefa árdua. Notei que os alunos apresentaram dificuldades em trabalhar em grupo, quais estratégias você pode utilizar para melhorar essa situação?

Aluno A6: A9,

Obrigado pelo elogio à minha reflexão. Mas em relação às dificuldades encontrada na intervenção com relação ao trabalho em grupo, a princípio a minha estratégia será trabalhar com os alunos individualmente, até que eu possa encontra uma outra forma de fazer com que eles gostem e percebam que trabalhar em grupo pode ajudá-los a compreender o conteúdo, pois estarão discutindo sobre o mesmo. Com certeza vou descobrir como fazer isso. A6

Aluno A10: A6, Parabéns pela sua reflexão. Se você fosse dar esta aula de novo o que você faria de diferente?

A10, Obrigado pelo elogio. Em relação aula eu me certificaria se todo material a ser usado estava ok, tentaria chegar um pouco mais cedo para últimos ajustes e com certeza agora vou ter sempre uma segunda opção para não perder tempo como na última. A6

Professor PP! Muito boa suas reflexões, dilemas e etnométodos. Você realmente está refletindo sobre a sua docência. Uma questão: Como você vem aprendendo a ser professora no contexto a escola e da sala de aula?
}

Este processo pode fortalecer a estruturação e elaboração de sucessivas reconstruções que fornecem suporte para a organização do sujeito enquanto agente em transformação. Diante disso, desenvolve-se um processo de dialogicidade, na qual professores e alunos vão tecendo a construção de novos conhecimentos que são reconstruídos a cada nova contribuição.

\section{Costurando alguns nós e abrindo outras brechas de pesquisa}

As reflexões teóricas mapeadas ao longo desse artigo, bem como suas análises iniciais, estão sintonizadas com o início da pesquisa doutoral realizada na Universidade Federal de Sergipe, sobre as narrativas em rede dos alunos integrantes do Pibid de Pedagogia da UESB de 
Jequié.

Acreditamos que o trabalho com as tecnologias digitais possibilitam uma maior comunicação e interação entre os sujeitos praticantes da proposta, superando uma concepção de comunicação pautada na mídia de massa para uma mídia mais interativa em rede.

Esse trabalho interativo desenvolvido no Pibid, pautado nas discussões de Moraes (1997), quando a autora coloca a importância das relações e conexões, onde é por meio da relação sujeito objeto que nasce o conhecimento. Além disso, para a autora o conhecimento em rede pressupões flexibilidade, plasticidade, interatividade, adaptabilidade, cooperação, parceria, apoio mútuo e auto-organização, aspectos que facilmente observamos na análise das narrativas das discentes. É um pensamento que enfatiza o contexto, propõe uma maior interação entre os sujeitos.

Nessa lógica, o trabalho com a formação inicial no contexto da cibercultura vivencia o desafio de compreender e experimentar diferentes interfaces, que nascem com o movimento contemporâneo da tecnologia, aprendendo com a não-linearidade do meio digital e a abertura a múltiplas manipulações proporcionadas pela comunicação interativa. Nossa prática pedagógica desenvolvida ao longo de dois anos no Pibid, comprova que não é possível o desenvolvimento de ações docentes em ambientes online, com base numa concepção de educação instrucionista, pois as TIC potencializam outra dinâmica de trabalho mais colaborativo e interativo.

\section{REFERÊNCIAS}

CONDORCET, J. A. N. de C. Cinco memórias sobre a instrução pública. São Paulo: UNESP, 2008.

DEMO, P. Instrucionismo e nova mídia. In: SILVA, M. (Org.). Educação Online. São Paulo: Loyola, 2003. p. 75- 88.

IMBERNÓN, F. Formação docente e profissional - formar-se para a mudança e a incerteza. São Paulo: Editora Cortez, 2005.

LOCKE, J. Carta acerca da tolerância; Segundo Tratado sobre o governo; Ensaio acerca do entendimento humano. São Paulo, Abril Cultural, 1983. (Coleção Os Pensadores).

LUCENA, S. Culturas digitais e tecnologias móveis na educação. Educar em Revista, Curitiba, Brasil, n. 59 p. 277-290, jan./mar. 2016.

MORAES, M. C. O paradigma educacional emergente. Campinas-SP, Papirus, 1997.

KENSKI, V. M. Tecnologias e ensino presencial e a distância. Campinas - SP: Papirus, 2003. 
PEREIRA, S. A. C. Saberes Docentes em Ambientes Virtuais de Aprendizagem. 2008. 208f. Dissertação (Mestrado em Educação). Universidade Federal da Bahia. Salvador, 2008.

PRETTO, N. Uma escola sem/com futuro: educação e multimídia Campinas-SP: Papirus, 1996.

PRIMO, A. Interação mediada por computador: comunicação, cibercultura, cognição. Porto Alegre: Sulina, 2007.

SILVA, M. Sala de aula Interativa. Rio de Janeiro: Quartet, 2002. 